\title{
Probabilistic Prediction of Aggregate Traffic Demand Using Uncertainty in Individual Flight Predictions
}

\author{
Eugene Gilbo* and Scott Smith ${ }^{\dagger}$ \\ Volpe National Transportation Systems Center, Cambridge, Massachusetts, 02142, USA
}

\begin{abstract}
[Abstract] Federal Aviation Administration (FAA) air traffic flow management (TFM) decision-making is based primarily on a comparison of deterministic predictions of demand and capacity at National Airspace System (NAS) elements such as airports, fixes and enroute sectors. The current Traffic Flow Management System (TFMS) and its decisionsupport tools ignore the stochastic nature of the predictions. Taking into account uncertainty in predictions and moving from deterministic to probabilistic TFM is an important part of the NextGen program that will help TFM specialists make better and more realistic decisions. This paper uses current TFMS data to analyze how uncertainty in prediction of arrival times for individual flights translates into uncertainty in prediction of aggregate traffic demand counts at arrival airports. A methodology was developed for probabilistic prediction of aggregate 15-minute demand counts by using the probability distributions of arrival time predictions for individual flights. A key element of the methodology is that the aggregate demand counts are predicted from extended sets of flights with the estimated times of arrival (ETAs) in both the interval of interest and several adjacent intervals. Numerical examples are presented that illustrate the difference between deterministic and probabilistic traffic demand predictions.
\end{abstract}

\section{Introduction}

Federal Aviation Administration (FAA) air traffic flow management (TFM) decision-making is based primarily on a comparison of deterministic demand and capacity predictions at various National Airspace System (NAS) elements such as airports, fixes and en-route sectors. The current Traffic Flow Management System (TFMS) and its decision-support tools ignore the stochastic nature of the predictions.

Taking into account uncertainty in predictions and moving from deterministic to probabilistic TFM is an important part of the Next Generation Air Transportation System (NextGen) program that will help TFM specialists make better and more realistic decisions.

During the past few years, the concept of probabilistic TFM has matured, with research producing evidence of the potential benefits of the transition from current deterministic to probabilistic TFM. Many organizations, such as FAA, NASA, MITRE, Metron Aviation, Sensis, Volpe Center and others, are currently engaged in research on probabilistic TFM.

Several publications have presented the concepts and potential applications of probabilistic TFM as well as modeling and benefit analysis $\left(\right.$ see $^{1-10}$ ). A general concept of probabilistic TFM and representation of uncertainty in air traffic demand and capacity predictions for identifying and managing congestion in NAS elements are well described in ${ }^{2-4}$. Research results presented in ${ }^{5,6}$ provide an important contribution to probabilistic TFM describing a constructive approach to incorporating probabilistic weather forecast into probabilistic TFM as well as design of the modeling tool for evaluating the TFM strategies. Papers ${ }^{7,8}$ describe a methodology for sequential decision-making approach to probabilistic TFM that makes it possible to update TFM strategies in accordance with updated probabilistic forecasts on demand and capacity.

It is important to note that the probabilistic TFM concepts will evolve to everyday TFM practice only if the decision support tools for probabilistic TFM are built on realistic data that reflects and quantifies existing uncertainty in the aviation system, namely uncertainty in predicting traffic demand and capacity for strategic TFM and tactical Air Traffic Control (ATC). This is why thorough data analysis along with analytical tools are needed to

\footnotetext{
* Operations Research Analyst, Traffic Flow Management Division, RVT-73

${ }^{\dagger}$ Operations Research Analyst, Systems Operations and Assessment Division, RVT-91
} 
analyze the sources of uncertainty, characterization of uncertainty and estimation of its parameters, the ways of reducing uncertainty and incorporating uncertainty into the TFM decision-making process.

This paper continues our previous research on the estimation and characterization of uncertainty in aggregate traffic demand predictions in the FAA Traffic Flow Management System (TFMS), formerly Enhanced Traffic Management System (ETMS). Our previous research (Ref. 9 and 10) was focused on analysis of accuracy of 15minute aggregate traffic demand predictions in TFMS and on the development of a regression model aimed at improving the accuracy and stability of those aggregate predictions. The analysis dealt with aggregate demand counts, and did not explicitly consider uncertainty in the prediction of events for individual flights. The regression model improved both the accuracy of demand predictions and the stability and accuracy of TFMS Monitor/Alert.

This paper analyzes how uncertainty in prediction of arrival times for individual flights translates into uncertainty in prediction of aggregate traffic demand counts at arrival airports. Like our previous work, it is based on a statistical analysis of current TFMS data. The translation of the characteristics of uncertainty in TFMS predictions for individual flights into characteristics of uncertainty in predictions for aggregate demand counts is a challenging problem.

Larry Meyn, in his pioneering publication ${ }^{1}$, proposed a methodology for obtaining probabilistic aggregate traffic demand prediction through characteristics of uncertainty in individual flight predictions. In Ref. 1, a recursive algorithm was presented for calculating the probability distribution of predicted aggregate traffic demand based on the probabilities of individual flights to be in the time interval of interest (e.g., 15-minute interval). It is worth mentioning that in Ref. 1 the set of candidate flights for probabilistic distribution of predicted aggregate demand included only the flights with the Estimated Time of Arrivals (ETAs) within the time interval of interest and did not include the flights with ETAs outside this interval. To estimate the benefits of probabilistic demand predictions over deterministic predictions, Meyn $^{1}$ used a Monte Carlo simulation. The simulation was conducted on artificial data (not actual air traffic data) and showed that the probabilistic approach provided more accurate predictions than the deterministic approach.

Some elements of the methodology from Ref. 1 are used in this paper. Unlike the study reported in Ref. 1, this study is based on current TFMS historical data. Extensive statistical analysis of TFMS data was performed to characterize the accuracy of predictions of airport arrival time for individual flights. Those characteristics were then used for probabilistic predictions of aggregate traffic demand for specific time intervals. A methodology was developed to determine the probability distribution of predicted aggregate 15-minute demand counts at arrival airports by using the probability distributions of errors in arrival time predictions for individual flights. A key element of the methodology is that it considers the extended set of candidate flights for those predictions, which includes the flights with ETAs both within the time interval of interest and outside the interval, namely, in several adjacent earlier and later intervals.

The paper presents a methodology and the corresponding techniques of how to use the data for probabilistic prediction of aggregate traffic demand at airports. Numerical examples are presented that illustrate the difference between deterministic and probabilistic traffic demand predictions as well as benefits of using extended sets of flights for improving accuracy of aggregate demand predictions.

This paper presents

- An analysis of the accuracy of TFMS flight-by-flight prediction data, data that forms the basis for probabilistic TFM. A clear understanding of where predictions are good today, and where they are not so good, will aid in the development of improved prediction algorithms.

- Given the probability distribution of flight arrival times, the probabilistic predictions of aggregate arrival demand counts at airports (e.g., 15-minute demand counts) are derived. This will provide a better understanding the relationship between the uncertainty in flight arrival times and the uncertainty in the 15minute counts used by TFMS, thus the likely impacts on TFMS of improved flight event predictions.

It is organized as follows.

- Section II describes the data that was used in this study.

- Section III examines the errors that TFMS makes when predicting flight airport arrival times. It summarizes these errors with empirical distributions.

- Section IV uses the probability distributions of errors in predictions of ETAs for individual flights (from Section III) to derive probability distributions of the number of airport arrivals in a 15 -minute interval. 
From this, probabilistic demand predictions for airport arrivals that comprise the mean demand and the area of uncertainty around the mean demand are obtained.

- Section $\mathrm{V}$ concludes the paper by summarizing the findings.

\section{Examined Flight-by-Flight Data}

TFMS continuously updates information on the status of each flight in the system and predicts each flight's time and location at various points along its origin-destination route. The TFMS flight list for a NAS element can be requested at any time. The flight list shows the flight's status (airborne or still on the ground), estimated time of departure (or actual departure time for an active flight), and estimated time of arrival at a NAS element, including destination airport. TFMS also collects flight-by-flight historical data that include both predictions and what actually happened.

On April 25 and 26, 2007, and again on June 7 and 8, 2007, TFMS list requests were repeatedly run for the nine airports ORD, ATL, DFW, LAX, MIA, BOS, SFO, STL, and MCI

These repeated list requests, which were run once every 15 minutes, generated flight-by-flight predictions for airport arrivals. Data were gathered for approximately 7 hours after 1200Z of April 25 and 26, 2007 and for approximately 12 hours after $1200 \mathrm{Z}$ of June 7 and 8 . April $25^{\text {th }}$ was a Wednesday and June $7^{\text {th }}$ was a Thursday.

For the airports on April 25-26, there were some 6,700 flights, with a total of 78,000 observations. (Each flight has multiple observations because predictions are made at various look-ahead times.) On June 7-8, there were approximately 6,000 flights, with a total of 93,000 observations.

Statistical analysis of flight data was performed to characterize uncertainty (errors) in flight arrival time predictions. Separate analysis was conducted for active (airborne) flights and for proposed flights (that are still on the ground) to characterize the difference in the accuracy of predictions depending on the flight's status.

\section{Analysis of TFMS Predictions of Flight's Arrival Time}

This section provides a descriptive statistical analysis of the accuracy of TFMS predictions that will be used in later sections. The analyses were conducted on historical data for individual flights collected at nine airports during two days in April and two days in June 2007. The primary figure of merit used is the accuracy of predicted flight arrival times at an airport (ETA), which is measured as an error (predicted - actual) in the arrival time.

First, we present the results of statistical analysis that were derived from processing an extended set of historical data, which consolidated the data from all nine airports considered in the study. We focused on look-ahead times (LAT) of between 1 and 3 hours, and the results are presented in Table 1. The results of statistical analysis of flight arrival data for each airport separately are then shown in Table 2.

Table 1 shows the distributions of (predicted - actual) airport arrival time, divided into the following time buckets:

- Less than -180 minutes (flights more than 3 hours late)

- $\quad-180$ to -61 minutes (flights $1-3$ hours late)

- -60 to -15 minutes (flights less than 1 hour late)

- On time (flights that are between 15 minutes late and 15 minutes early)

- 15 - 60 minutes (flights less than 1 hour early)

- $61-180$ minutes (flights $1-3$ hours early)

- Over 180 minutes (flights more than 3 hours early) 
Table 1 Airports: Distribution of Errors in Flight Arrival Time Predictions

\begin{tabular}{|c|c|c|c|c|c|c|c|c|c|c|}
\hline \multirow{3}{*}{ Month } & \multirow{3}{*}{ LAT } & \multirow{3}{*}{$\begin{array}{l}\text { Flight } \\
\text { Status }\end{array}$} & \multirow{3}{*}{$\begin{array}{l}\text { Number of } \\
\text { Observations }\end{array}$} & \multicolumn{7}{|c|}{ Time Bucket } \\
\hline & & & & \multicolumn{3}{|c|}{ Late (minutes) } & \multirow{2}{*}{$\underset{\text { Time }^{\ddagger}}{\text { On }}$} & \multicolumn{3}{|c|}{ Early (minutes) } \\
\hline & & & & $\begin{array}{l}\text { Over } \\
180\end{array}$ & $\begin{array}{l}61- \\
180\end{array}$ & $\begin{array}{l}15- \\
60\end{array}$ & & $\begin{array}{l}15- \\
60\end{array}$ & $\begin{array}{l}61- \\
180\end{array}$ & $\begin{array}{l}\text { Over } \\
180\end{array}$ \\
\hline April & $1-2 \mathrm{hr}$ & A & 7476 & $0.0 \%$ & $0.1 \%$ & $4.4 \%$ & $92.6 \%$ & $2.0 \%$ & $0.0 \%$ & $0.9 \%$ \\
\hline June & $1-2 \mathrm{hr}$ & A & 8123 & $0.1 \%$ & $0.2 \%$ & $4.5 \%$ & $92.7 \%$ & $2.5 \%$ & $0.0 \%$ & $0.1 \%$ \\
\hline April & $2-3 \mathrm{hr}$ & A & 5699 & $0.0 \%$ & $0.0 \%$ & $4.5 \%$ & $91.0 \%$ & $3.9 \%$ & $0.1 \%$ & $0.4 \%$ \\
\hline June & $2-3 \mathrm{hr}$ & A & 4605 & $0.1 \%$ & $0.2 \%$ & $4.8 \%$ & $89.7 \%$ & $4.9 \%$ & $0.3 \%$ & $0.1 \%$ \\
\hline April & $1-2 \mathrm{hr}$ & $\mathrm{P}$ & 12605 & $0.2 \%$ & $5.7 \%$ & $25.6 \%$ & $59.9 \%$ & $6.9 \%$ & $1.3 \%$ & $0.4 \%$ \\
\hline June & $1-2 \mathrm{hr}$ & $\mathrm{P}$ & 7159 & $0.9 \%$ & $10.6 \%$ & $30.2 \%$ & $53.4 \%$ & $4.1 \%$ & $0.2 \%$ & $0.4 \%$ \\
\hline April & $2-3 \mathrm{hr}$ & $\mathrm{P}$ & 10490 & $0.3 \%$ & $4.8 \%$ & $25.3 \%$ & $59.0 \%$ & $9.0 \%$ & $0.6 \%$ & $1.0 \%$ \\
\hline June & $2-3 \mathrm{hr}$ & $\mathrm{P}$ & 12382 & $1.1 \%$ & $10.4 \%$ & $27.7 \%$ & $52.8 \%$ & $7.0 \%$ & $0.6 \%$ & $0.3 \%$ \\
\hline
\end{tabular}

Table 1 represents a high level distribution of flight arrival time prediction errors. For active flights (Flight Status A), there is no significant difference in prediction accuracy between April and June data: 89.7 to 92.7 percent of flights are on time, and almost all prediction errors are within \pm 1 hour range. For proposed flights (Flight Status P), however, there is an obvious difference between April and June data. In April, there is a higher percentage "on time" predictions than in June: close to $60 \%$ in April vs. $53 \%$ in June. Additionally, in April, there is a lower percentage of late predictions than in June: approximately $30 \%$ in April vs. approximately $40 \%$ in June for late predictions. The difference between April and June predictions can be explained by the impact of traffic management initiatives (TMIs). A review of TMIs in April and June revealed a high number of ground stops on one of the June study dates (June $8^{\text {th }}$ ), which included several ground stops at the studied airports: 3 in ATL, 1 at DFW, MIA, ORD and SFO.

Closer examination of the data revealed that

- The prediction accuracy of airport arrival times for active flights is significantly better than for proposed flights that are still on the ground: for active flights, the prediction errors are within a \pm 15 -minute range, whereas for the proposed flights, the prediction errors are within a range from - $45 \mathrm{~min}$ to $25 \mathrm{~min}$.

- Within each case of active and proposed flights, the prediction accuracy is nearly the same for LAT $=1-2$ hours and LAT $=2-3$ hours.

- For active flights, the distributions of prediction errors are nearly symmetric with zero average error.

- For the flights still on the ground, the distributions of prediction errors are biased (with median error of approximately -7 minutes) and asymmetric with heavier left-hand tails that reflect the tendency for proposed flights to arrive, on average, later than predicted. Note: negative prediction error indicates that flight's actual arrival time is later than predicted.

Figure 1 shows the cumulative probability distribution of prediction errors obtained from the combined historical data set that included the data for both active and proposed flights with look-ahead time prediction from 1 to 2 hours. The distribution is biased (with median error of approximately -3 minutes) and asymmetric with a heavier left-hand tail, toward late arrivals.

\footnotetext{
$¥$ "On-time" is considered to be within 15 minutes (early or late) of the predicted time.
} 


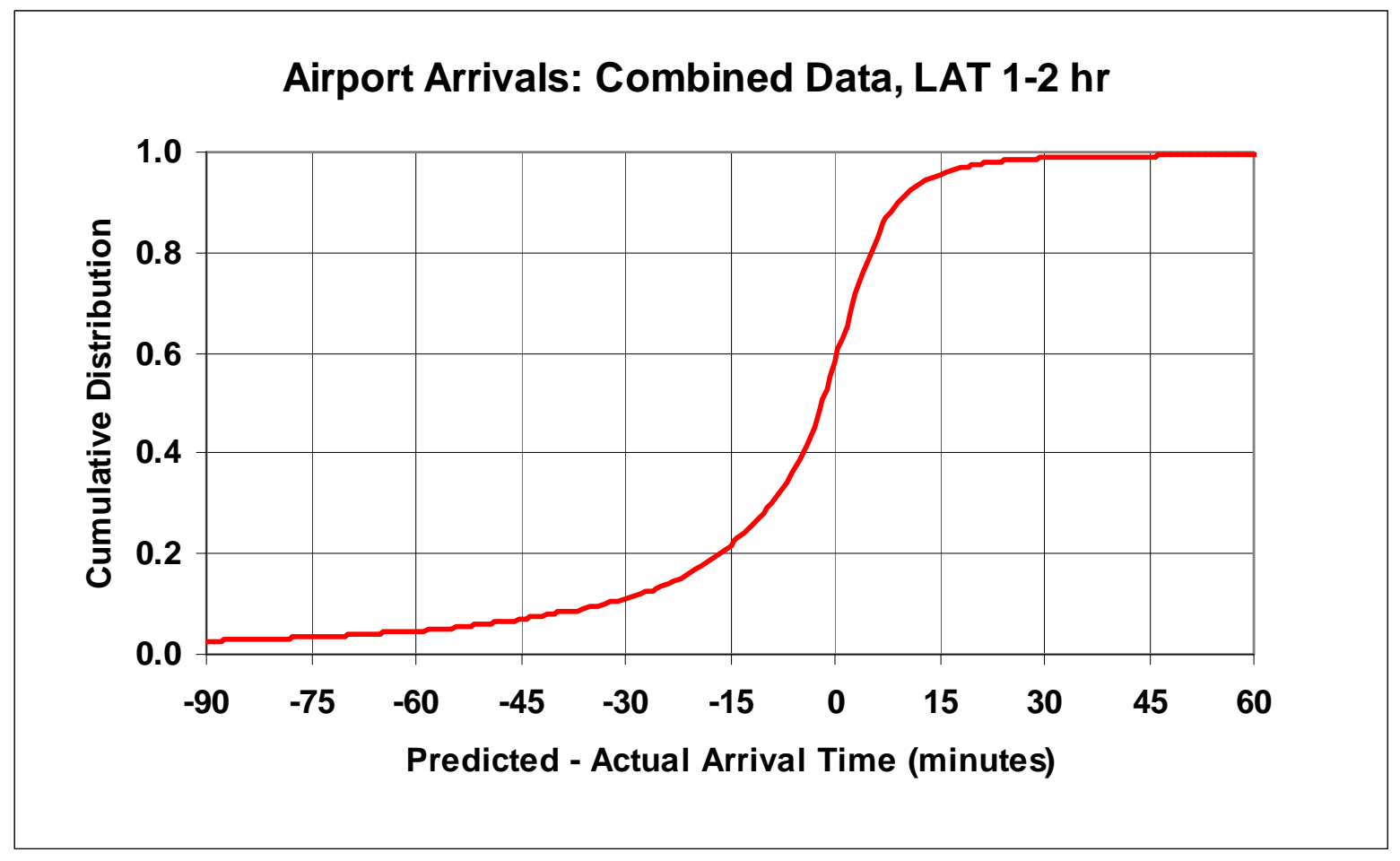

Figure 1. Cumulative Distribution of Errors in Flight Arrival Time Predictions

Table 2 presents the results of statistical analysis of accuracy of flight arrival time predictions at each of nine airports considered in this study. Here again, there are significant differences in airport flight arrival time prediction accuracy between active and proposed flights. The differences are not only in absolute values of prediction errors (predictions for active flights are significantly more accurate than for proposed flights) but also in their signs: flights on the ground tend to arrive later than predicted, but the airborne flights tend to arrive earlier. This is because uncertainty in flight departure time, mostly with additional delays on the ground at the origin airport, adds to later arrival for proposed flights.

The differences in average prediction errors vary by airport. In April, when there were many fewer TMIs than in June, the prediction error values for proposed flights at different airports are smaller than in June. There is, however, not much difference in prediction accuracy for active flights in April and June. For example, in April, the prediction errors with LAT $=1-2$ hours for the proposed flights vary from -13.9 to -10.6 minutes at seven of nine airports (except LAX and MIA with -5.9 and -5.2 minutes, respectively). For the active flights with LAT $=1-2$ hours, the average prediction errors vary from nearly zero to 3.9 minutes at seven of nine airports (with the exception of 7.4 minute early arrivals at MIA and 7.5 minute late arrivals at ORD). A relatively wider range of average prediction errors among airports occurred for LAT $=2-3$ hours.

There is not much difference between LAT $=1-2$ hour and LAT $=2-3$ hour predictions within each case of flights' status. However, there is a large difference in accuracy of prediction for flights still on the ground in April and June, when the June predictions are significantly less accurate than for April. The high number of ground stops on June $8^{\text {th }}$ was noted earlier.

Table 2. (Predicted-Actual) Arrival Time (minutes)

\begin{tabular}{|c|c|c|c|c|c|c|c|}
\hline Month & LAT & Status & $\begin{array}{c}\text { Dest. } \\
\text { Airport }\end{array}$ & $\begin{array}{c}\text { Number of } \\
\text { Observations }\end{array}$ & $\begin{array}{c}\text { Average } \\
\text { Error }\end{array}$ & $\begin{array}{c}\text { Standard } \\
\text { Deviation }\end{array}$ & Skewness \\
\hline April & $1-2 \mathrm{hr}$ & A & ATL & 1832 & 2.2 & 7.2 & -2.3 \\
\hline June & $1-2 \mathrm{hr}$ & A & ATL & 1822 & 1.4 & 10.1 & -2.2 \\
\hline April & $2-3 \mathrm{hr}$ & A & ATL & 916 & 4.2 & 6.9 & -1.6 \\
\hline June & $2-3 \mathrm{hr}$ & A & ATL & 689 & 2.6 & 13.2 & 1.1 \\
\hline April & $1-2 \mathrm{hr}$ & P & ATL & 3336 & -11 & 23.1 & -1.4 \\
\hline
\end{tabular}

5

American Institute of Aeronautics and Astronautics 


\begin{tabular}{|c|c|c|c|c|c|c|c|}
\hline Month & LAT & Status & $\begin{array}{c}\text { Dest. } \\
\text { Airport }\end{array}$ & $\begin{array}{l}\text { Number of } \\
\text { Observations }\end{array}$ & $\begin{array}{c}\text { Average } \\
\text { Error }\end{array}$ & $\begin{array}{l}\text { Standard } \\
\text { Deviation }\end{array}$ & Skewness \\
\hline June & $1-2 \mathrm{hr}$ & $\mathrm{P}$ & ATL & 1721 & -32 & 42.1 & -1.2 \\
\hline April & $2-3 \mathrm{hr}$ & $P$ & ATL & 2023 & -1.7 & 19.4 & -1.6 \\
\hline June & $2-3 \mathrm{hr}$ & $P$ & ATL & 2816 & -27.4 & 41.5 & -1.2 \\
\hline April & $1-2 \mathrm{hr}$ & A & BOS & 659 & 0 & 6.8 & -1.9 \\
\hline June & $1-2 \mathrm{hr}$ & $\bar{A}$ & BOS & 526 & 1.7 & 5.1 & -0.1 \\
\hline April & $2-3 \mathrm{hr}$ & $\bar{A}$ & BOS & 373 & 0 & 8.4 & -1.5 \\
\hline June & $2-3 \mathrm{hr}$ & A & BOS & 320 & 1.9 & 9.2 & -3 \\
\hline April & $1-2 \mathrm{hr}$ & $P$ & BOS & 1280 & $\begin{array}{l}-12.9 \\
\end{array}$ & 23.5 & -1.4 \\
\hline June & $1-2 \mathrm{hr}$ & $\mathrm{P}$ & BOS & 727 & -22.2 & 36.1 & -1.6 \\
\hline April & $2-3 \mathrm{hr}$ & $\mathrm{P}$ & BOS & 880 & -10.3 & 23.8 & -0.9 \\
\hline June & $2-3 \mathrm{hr}$ & $\mathrm{P}$ & BOS & 1057 & -21.9 & 38.1 & -1.4 \\
\hline April & $1-2 \mathrm{hr}$ & A & DFW & 1300 & 3.9 & 6.5 & 2 \\
\hline June & $1-2 \mathrm{hr}$ & A & DFW & 1498 & 1.7 & 5.5 & 1 \\
\hline April & $2-3 \mathrm{hr}$ & A & DFW & 1397 & 1.9 & 7.6 & 6.3 \\
\hline June & $2-3 \mathrm{hr}$ & A & DFW & 735 & 2.3 & 8.4 & 1.2 \\
\hline April & $1-2 \mathrm{hr}$ & $P$ & DFW & 1776 & -10.6 & 20.6 & -1.2 \\
\hline June & $1-2 \mathrm{hr}$ & $\mathrm{P}$ & DFW & 969 & -15 & 30.2 & -2.9 \\
\hline April & $2-3 \mathrm{hr}$ & $\mathrm{P}$ & DFW & 2239 & -12.2 & 21.8 & -1.3 \\
\hline June & $2-3 \mathrm{hr}$ & $\mathrm{P}$ & DFW & 2116 & -15.4 & 29.7 & -2.4 \\
\hline April & $1-2 \mathrm{hr}$ & A & LAX & 617 & 0 & 5 & -1.5 \\
\hline June & $1-2 \mathrm{hr}$ & A & LAX & 1006 & -0.9 & 7 & -9.4 \\
\hline April & $2-3 \mathrm{hr}$ & A & LAX & 694 & -0.8 & 4.9 & -1.9 \\
\hline June & $2-3 \mathrm{hr}$ & $\bar{A}$ & LAX & 921 & -2 & 11 & -9.4 \\
\hline April & $1-2 \mathrm{hr}$ & $\mathrm{P}$ & LAX & 1032 & -5.9 & 16.2 & -2.1 \\
\hline June & $1-2 \mathrm{hr}$ & $\mathrm{P}$ & LAX & 753 & $\begin{array}{l}-9.3 \\
\end{array}$ & 15.8 & -1.9 \\
\hline April & $2-3 \mathrm{hr}$ & $\mathrm{P}$ & LAX & 882 & -7.2 & 20.6 & -2 \\
\hline June & $2-3 \mathrm{hr}$ & $\mathrm{P}$ & LAX & 1216 & -6.5 & 18 & -1.9 \\
\hline April & $1-2 \mathrm{hr}$ & $\mathrm{A}$ & MCI & 286 & 1.4 & 5.6 & -2.5 \\
\hline June & $1-2 \mathrm{hr}$ & $\bar{A}$ & MCI & 262 & 1.7 & 7.9 & 0.2 \\
\hline April & $2-3 \mathrm{hr}$ & A & MCI & 262 & 2 & 3.9 & -0.4 \\
\hline June & $2-3 \mathrm{hr}$ & $\mathrm{A}$ & MCI & 113 & 4.7 & 12.6 & 1.3 \\
\hline April & $1-2 \mathrm{hr}$ & $\mathrm{P}$ & MCI & 710 & -11.8 & 18.8 & $\begin{array}{l}-1.3 \\
\end{array}$ \\
\hline June & $1-2 \mathrm{hr}$ & $\mathrm{P}$ & MCI & 352 & -18.4 & 24.1 & -1.5 \\
\hline April & $2-3 \mathrm{hr}$ & $\mathrm{P}$ & MCI & 517 & -13.7 & 19.7 & $\begin{array}{l}-0.8 \\
\end{array}$ \\
\hline June & $2-3 \mathrm{hr}$ & $\mathrm{P}$ & MCI & 625 & -21.6 & 30.9 & $\begin{array}{l}-1.8 \\
\end{array}$ \\
\hline April & $1-2 \mathrm{hr}$ & A & MIA & 541 & 7.4 & 7.7 & -1 \\
\hline June & $1-2 \mathrm{hr}$ & $\mathrm{A}$ & MIA & 624 & -0.5 & 14.4 & -1.6 \\
\hline April & $2-3 \mathrm{hr}$ & $\mathrm{A}$ & MIA & 694 & 7.4 & 12 & 5 \\
\hline June & $2-3 \mathrm{hr}$ & A & MIA & 319 & 0.1 & 22.3 & 1.8 \\
\hline April & $1-2 \mathrm{hr}$ & $P$ & MIA & 757 & -5.2 & 28.2 & $\begin{array}{l}-0.9 \\
\end{array}$ \\
\hline June & $1-2 \mathrm{hr}$ & $\mathrm{P}$ & MIA & 575 & -19 & 35.4 & -1 \\
\hline April & $2-3 \mathrm{hr}$ & $\mathrm{P}$ & MIA & 1213 & -6.6 & 27.4 & -0.7 \\
\hline June & $2-3 \mathrm{hr}$ & $\mathrm{P}$ & MIA & 895 & $\begin{array}{l}-21.3 \\
\end{array}$ & 36 & -0.6 \\
\hline April & $1-2 \mathrm{hr}$ & $\mathrm{A}$ & ORD & 1178 & $\begin{array}{l}-7.5 \\
\end{array}$ & 11.1 & $\begin{array}{l}-4.1 \\
\end{array}$ \\
\hline June & $1-2 \mathrm{hr}$ & A & ORD & 1449 & -3.9 & 11 & -3.2 \\
\hline April & $2-3 \mathrm{hr}$ & A & ORD & 826 & -6.5 & 11.5 & 0.1 \\
\hline June & $2-3 \mathrm{hr}$ & $\mathrm{A}$ & ORD & 891 & -3.6 & 11.2 & -0.6 \\
\hline April & $1-2 \mathrm{hr}$ & $\mathrm{P}$ & ORD & 1263 & -13.9 & 43.6 & 0.9 \\
\hline June & $1-2 \mathrm{hr}$ & $\mathrm{P}$ & ORD & 977 & -22.3 & 40.1 & -1.1 \\
\hline April & $2-3 \mathrm{hr}$ & $\mathrm{P}$ & ORD & 1227 & -10.1 & 31.6 & 0.4 \\
\hline June & $2-3 \mathrm{hr}$ & $\mathrm{P}$ & ORD & 1963 & -19.6 & 43.7 & -0.5 \\
\hline April & $1-2 \mathrm{hr}$ & $\mathrm{A}$ & SFO & 515 & -0.4 & 8.3 & -1.7 \\
\hline
\end{tabular}

American Institute of Aeronautics and Astronautics 


\begin{tabular}{|c|c|c|c|c|c|c|c|}
\hline Month & LAT & Status & $\begin{array}{c}\text { Dest. } \\
\text { Airport }\end{array}$ & $\begin{array}{c}\text { Number of } \\
\text { Observations }\end{array}$ & $\begin{array}{c}\text { Average } \\
\text { Error }\end{array}$ & $\begin{array}{c}\text { Standard } \\
\text { Deviation }\end{array}$ & Skewness \\
\hline June & $1-2 \mathrm{hr}$ & $\mathrm{A}$ & SFO & 608 & -0.4 & 5.5 & 0.4 \\
\hline April & $2-3 \mathrm{hr}$ & $\mathrm{A}$ & SFO & 260 & -2.4 & 8.6 & -1 \\
\hline June & $2-3 \mathrm{hr}$ & $\mathrm{A}$ & SFO & 489 & -2.7 & 7.4 & 0.9 \\
\hline April & $1-2 \mathrm{hr}$ & $\mathrm{P}$ & SFO & 1132 & -11.5 & 24.5 & -1.3 \\
\hline June & $1-2 \mathrm{hr}$ & $\mathrm{P}$ & SFO & 515 & -12.3 & 23.5 & -2.3 \\
\hline April & $2-3 \mathrm{hr}$ & $\mathrm{P}$ & SFO & 507 & -19.1 & 29.9 & -0.9 \\
\hline June & $2-3 \mathrm{hr}$ & $\mathrm{P}$ & SFO & 780 & -8.5 & 20.4 & -2.5 \\
\hline April & $1-2 \mathrm{hr}$ & $\mathrm{A}$ & STL & 480 & 1.7 & 5 & 0.9 \\
\hline June & $1-2 \mathrm{hr}$ & $\mathrm{A}$ & STL & 315 & 5.4 & 8.4 & 1.1 \\
\hline April & $2-3 \mathrm{hr}$ & $\mathrm{A}$ & STL & 254 & 2 & 8.2 & 1.2 \\
\hline June & $2-3 \mathrm{hr}$ & $\mathrm{A}$ & STL & 121 & 11.7 & 14.1 & 0.9 \\
\hline April & $1-2 \mathrm{hr}$ & $\mathrm{P}$ & STL & 1019 & -12.5 & 22.1 & -1.5 \\
\hline June & $1-2 \mathrm{hr}$ & $\mathrm{P}$ & STL & 470 & -16.1 & 26.5 & -1.6 \\
\hline April & $2-3 \mathrm{hr}$ & $\mathrm{P}$ & STL & 779 & -13.9 & 23.3 & -1.4 \\
\hline June & $2-3 \mathrm{hr}$ & $\mathrm{P}$ & STL & 739 & -15.2 & 26.5 & -1.6 \\
\hline
\end{tabular}

\section{Probabilistic Count Predictions}

\section{A. Introduction}

Previous sections analyzed uncertainty in predicting airport arrival times for individual flights. These results will now be used for probabilistic prediction of airport arrival demand counts.

The steps taken in this section are as follows:

1) Translate a flight's arrival time predictions and associated prediction errors into the probabilities for the flight to arrive in particular 15-minute time intervals.

2) Show how these probabilities can be combined to develop probabilistic count predictions for an interval from a set of flights with ETAs in the interval and in adjacent intervals (using the analytical approach described in Meyn ${ }^{1}$ ).

3) Simplify this approach by decomposing a set of candidate flights and considering the normal approximation to the binomial distribution. Derive means and standard deviations of demand counts.

4) Show how the derived probabilistic count predictions relate to the empirically observed, deterministic count predictions.

\section{B. Probability for a Flight to Arrive During a Specified Interval}

Consider a flight that is deterministically forecast to arrive at an airport at time $\mathbf{x}$, i.e., $\mathbf{x}$ is equal to a flight's ETA. What is the probability that the flight will arrive during the interval $[\mathbf{a}, \mathbf{b})^{\S}$ ? We denote this conditional probability as Prob(Arrive in $[\mathbf{a}, \mathbf{b}) \mid$ fc at time $\mathbf{x}$ ), where "fc" means forecast. Note: when we say "the probability that the flight will arrive during the interval" we mean the probability for the flight to be available to land during the interval, and, hence, to be counted in the aggregate demand prediction for this interval.

Considering the errors in flight's arrival time prediction (presented in Section III), the flight can arrive during the interval in question if the prediction error is between $\mathbf{x}-\mathbf{b}$ and $\mathbf{x}-\mathbf{a}$. Using the cumulative probability distribution function $(\mathrm{CDF})$ of prediction error presented in Figure 1, this probability can be determined as follows:

$\operatorname{Prob}($ Arrive in $[\mathbf{a}, \mathbf{b}) \mid$ fc at time $\mathbf{x})=\operatorname{CDF}(\mathbf{x}-\mathbf{a})-\operatorname{CDF}(\mathbf{x}-\mathbf{b})$.

For example, if $\mathbf{x}=1140, \mathbf{a}=1200$ and $\mathbf{b}=1215$, the flight can arrive in the $[1200,1215)$ interval if it is 20 to 35 minutes late, that is, if its "Predicted - Actual" time is between - 20 and - 35 minutes. This probability is

Prob(Arrive in $[1200,1215) \mid$ fc at time 1140) $=\mathrm{CDF}(-20)-\mathrm{CDF}(-35)$.

$\S$ The left bracket "[" indicates that the interval includes a, while the right parentheses ")" indicates that the interval goes up to but does not include $\mathbf{b}$.

American Institute of Aeronautics and Astronautics 
In a second example, $\mathbf{x}=1205, \mathbf{a}=1200$ and $\mathbf{b}=1215$. Here, the flight can arrive in the $[1200,1215)$ interval if it is between 5 minutes early and 10 minutes late; that is, if its "Predicted - Actual" time is between 5 and -10 minutes. This probability is

Prob(Arrive in $[1200,1215) \mid \mathrm{fc}$ at time 1205) $=\mathrm{CDF}(5)-\mathrm{CDF}(-10)$.

Figure 2 illustrates how the probabilities relate to the CDF for these two examples. In the first example, the probability is equal to $(\mathrm{CDF}(-20)-\mathrm{CDF}(-35))$ and is approximately $8 \%$ (the short vertical red line). In the second example, the probability is equal to $(\mathrm{CDF}(5)-\mathrm{CDF}(-10))$ and is approximately $50 \%$ (the longer vertical green line).

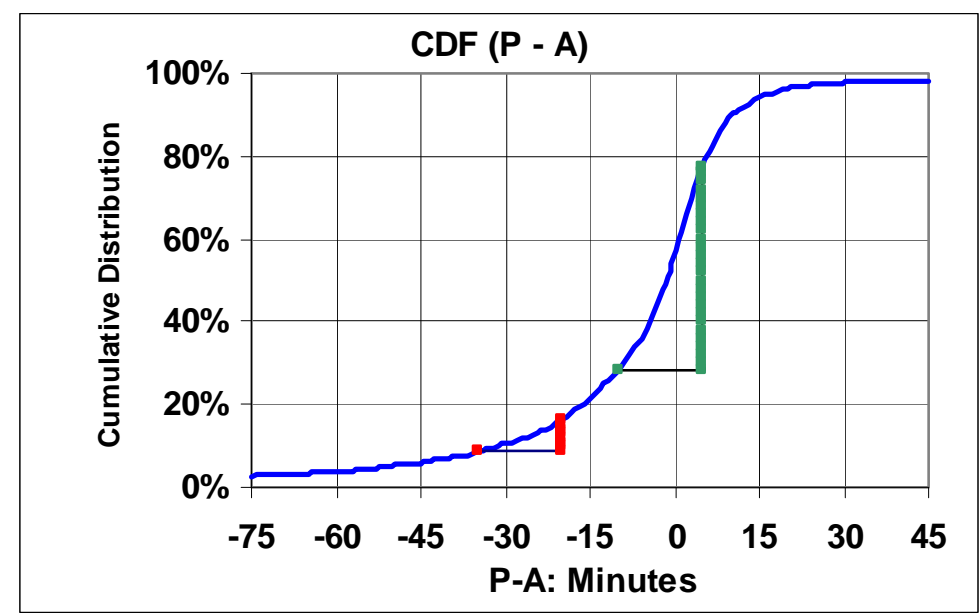

Figure 2. Predicted-Actual (P-A) Time and Flight Arrival Probability

The red curve in Figure 3 illustrates the distribution of probabilities for individual flights to arrive at [1200, 1215) interval as a function of predicted arrival time $\mathbf{x}$. This curve, which is simply a plot of all of the possible vertical lines from Figure 2 makes it possible to determine the probability for a flight with a forecast arrival time $\mathbf{x}$ to arrive in the $[1200,1215)$ interval. These probabilities depend on how far the forecast arrival time is from the 15minute interval of interest for arrivals: the farther the time $\mathbf{x}$ from the 15-minute interval the smaller the probability is for the flight to arrive during the interval. Using the two previous examples, if $\mathbf{x}$ is 1140 , the probability is $8 \%$; if $\mathbf{x}$ is 1205 , the probability is $50 \%$.

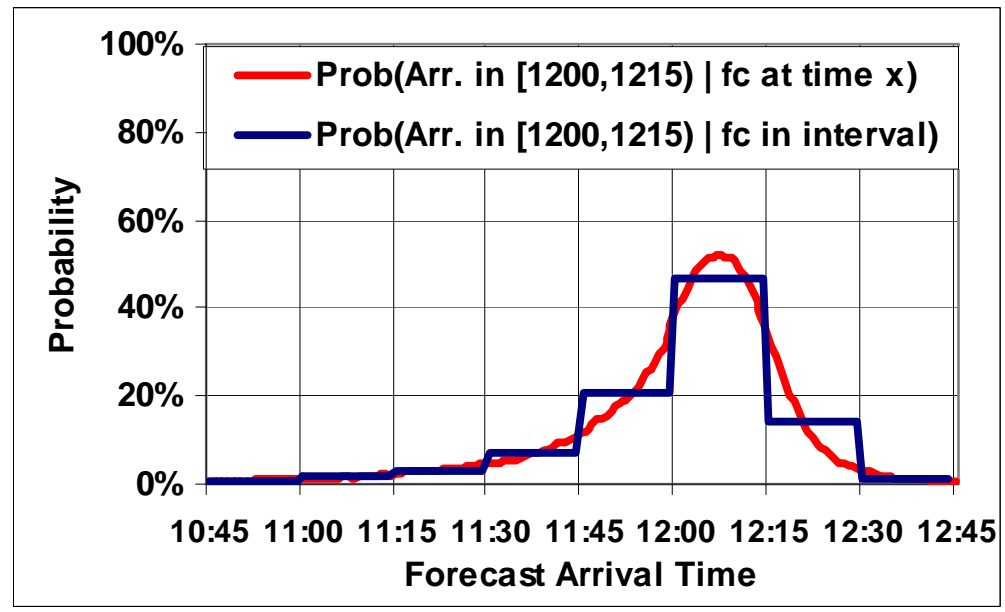

Figure 3. Relationship between Flight Arrival Probability and Estimated Arrival Time 
It is worth noticing that the major reason for determining probabilities for individual flights to arrive in a specific 15-minute interval is to later use those probabilities to aggregate the flights and then develop a probabilistic prediction of aggregate 15-minute demand counts. One could calculate the probabilistic distribution of aggregate traffic demand by using different probabilities for individual flights (see Meyn ${ }^{1}$ ). However, this will require cumbersome computations if many flights are involved. Therefore, to simplify the computational procedure, we will work with the probabilities that are the same for each flight in a group of flights predicted to arrive within a particular 15-minute interval, not at the particular time $\mathbf{x}$. As a result, the probabilities for individual flights will be different only when they are predicted to arrive in different 15 -minute intervals. Those probabilities can be obtained from the distribution of probabilities to arrive within a particular 15-minute interval as a function of time $\mathbf{x}$ (see the red curve in Figure 3) through the step-wise approximation of the curve so that the function remains constant within each 15-minute interval. The step-wise approximation is shown in Figure 3 by the blue line. The constant values for the approximation can be determined

- by averaging the red function at each 15-minute interval, or

- by assigning a constant probability in accordance with the allocation of predicted arrival times for individual flights within the interval.

The step-wise approximation makes it easier to deal with the number of flights that are forecast to arrive in the 15 -minute interval $[\mathbf{y}, \mathbf{y}+15)$. The constant value that corresponds to this interval determines the probability for each flight predicted at this interval to arrive within the $[\mathbf{a}, \mathbf{a}+15)$ interval. This probability is denoted as

$$
\text { Prob(Arrive in }[\mathbf{a}, \mathbf{a}+15) \mid \mathrm{fc} \text { in }[\mathbf{y}, \mathbf{y}+15)) \text {. }
$$

For example, Figure 3 gives the following probabilities for individual flights to arrive in $[1200,1215)$ interval if they are forecasted to arrive at various 15 -minute intervals:

$$
\begin{aligned}
& \text { Prob(Arrive in }[1200,1215) \mid \mathrm{fc} \text { in }[1130,1145))=0.07 \\
& \text { Prob(Arrive in }[1200,1215) \mid \mathrm{fc} \text { in }[1145,1200))=0.21 \\
& \text { Prob(Arrive in }[1200,1215) \mid \mathrm{fc} \text { in }[1200,1215))=0.47 \\
& \text { Prob(Arrive in }[1200,1215) \mid \mathrm{fc} \text { in }[1215,1230))=0.14
\end{aligned}
$$

Note that if the flight is forecast to arrive in the interval $[1200,1215)$, it has slightly less than $50 \%$ probability of arriving in that interval.

\section{Combining Probabilistic Count Predictions: a General Approach}

In the previous section, we examined the probability for an individual flight to arrive within a given interval, given its forecast arrival time. In this section, we briefly introduce Meyn's ${ }^{1}$ method for combining probabilistic count predictions from probabilities for individual flights.

Suppose that for certain set of flights (e.g., $\mathrm{N}$ flights), the probabilities for each individual flight to arrive at a NAS element (e.g., an airport) during a time interval are known, so that the probability for flight $\mathrm{i}$ to arrive during the time interval is equal to $p_{i}(i=1,2, \ldots, N)$. For example, if flight $i$ is predicted to arrive at 1205 , and our interval of interest is $1200-1215$, then the previous section (IV.B) tells us that $\mathrm{p}_{\mathrm{i}}=0.50$. Given the probabilities $\mathrm{p}_{\mathrm{i}}$ for individual flights, the probability distribution of demand counts will then be calculated, which will determine probability of each possible demand forecast count from 0 to $\mathrm{N}$ out of $\mathrm{N}$ flights. As a result, a set of probabilities $\mathrm{P}_{\mathrm{N}}[\mathrm{k}]$ that $\mathrm{k}$ of $\mathrm{N}$ flights are predicted to arrive at an airport determine the probabilistic demand forecast $(\mathrm{k}=0,1,2$, $\ldots, \mathrm{N})$. Assuming that the events for flights to arrive at an airport are independent, the following recursive procedure for calculating probabilities $\mathrm{P}_{\mathrm{N}}[\mathrm{k}]$ was presented in ${ }^{1}$ :

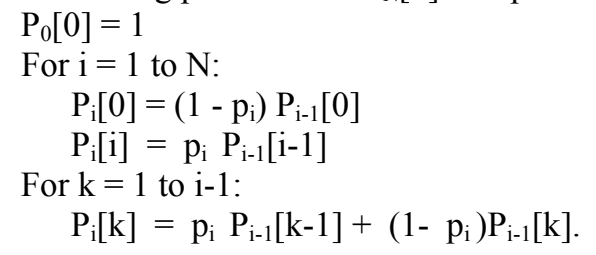


This procedure covers a general case when the probabilities $p_{i}(i=1,2, \ldots, N)$ are different. When all flights have the same probability $\mathrm{p}_{\mathrm{i}}=\mathrm{p}(\mathrm{i}=1,2, \ldots, \mathrm{N})$ to arrive at an airport, the above recursive procedure reduces to binomial distribution with parameters $\mathrm{N}$ and $\mathrm{p}$ :

$\mathrm{P}_{\mathrm{N}}[\mathrm{k}]=\frac{N !}{k !(N-k) !} \mathrm{p}^{\mathrm{k}}(1-\mathrm{p})^{\mathrm{N}-\mathrm{k}}, \mathrm{k}=0,1,2,3, \ldots, \mathrm{N}$

where $\mathrm{k} !=1 * 2 * 3 * \ldots * \mathrm{k}$, and $0 !=1$.

In the next section, we develop a closed-form probabilistic count prediction that makes use of this binomial property.

\section{A Tractable Probabilistic Count Prediction}

Consider the set of aircraft that might arrive during the interval $[\mathbf{a}, \mathbf{a}+15)$. The set may include the flights that are predicted to arrive during [a, $\mathbf{a}+15$ ), flights predicted to arrive during adjacent intervals, and other flights, such as pop-ups. To calculate the probability distribution of the number of aircraft predicted to arrive during this interval, one could consider each aircraft individually with its own probability to arrive in the time interval of interest, and use Meyn's approach ${ }^{1}$ to develop the probabilistic prediction. This would lead, however, to a cumbersome computational procedure.

Here we present an approximate alternative approach that simplifies the computations and allows for an easy way of obtaining probability distributions of traffic demand counts. The idea is to decompose the set of candidate flights to several sub-sets, each of which consists of a group of flights with the ETAs within the same 15-minute bucket (see Section IV.B). Within a group, each flight will have the same constant probability to arrive in the time interval of interest in accordance with the step-wise approximation of the probability function presented in Figure 3. Figure 4 illustrates how flights might be grouped by forecast arrival time.

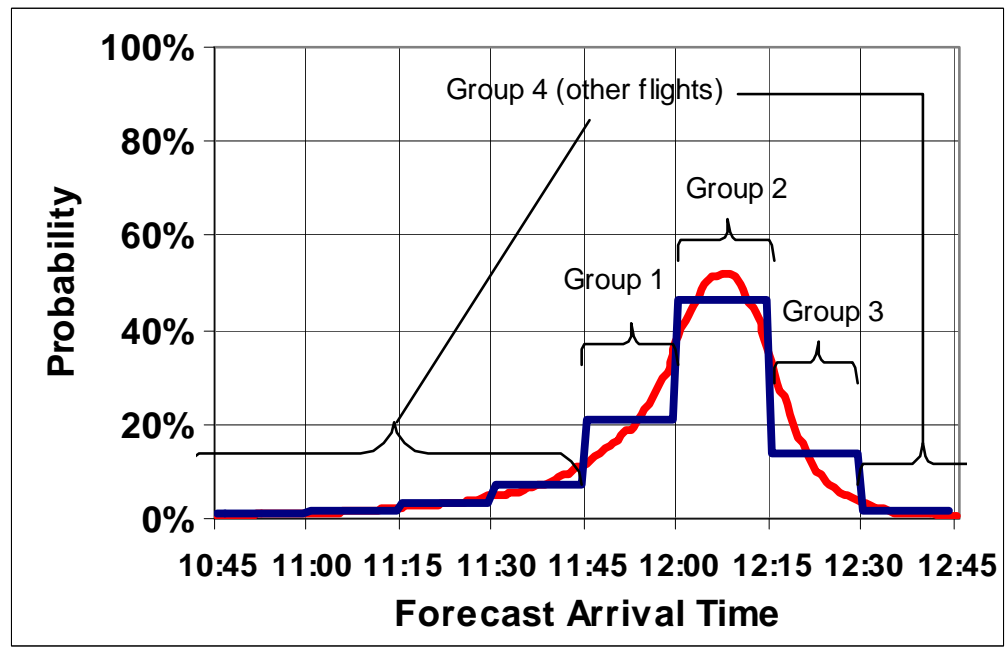

Figure 4. Flight Groupings

Suppose that the ETAs of flights in the entire set of selected candidate flights to arrive at the $[a, a+15)$ interval are allocated in $\mathrm{J}$ fifteen-minute buckets (including the interval of interest) so that the entire set of $\mathrm{N}$ flights can be grouped in $\mathrm{J}$ groups. Each group contains $\mathrm{n}_{\mathrm{j}}$ flights, each of which has a probability to arrive $\mathrm{p}_{\mathrm{j}}$ to arrive during the 15 -minute interval of interest $(j=1,2, \ldots, J)$, so that

$$
\sum_{j=1}^{J} n_{j}=\mathrm{N}
$$


The number of aircraft from a group $\mathrm{j}$ that might arrive during the interval $[\mathbf{a}, \mathbf{a}+15)$ is a binomially distributed random variable, with parameters $n_{j}$ and $p_{j}$ :

$\mathrm{P}_{\mathrm{nj}}[\mathrm{k}]=\frac{n_{j} !}{k !\left(n_{j}-k\right) !} \mathrm{p}_{\mathrm{j}}^{\mathrm{k}}\left(1-\mathrm{p}_{\mathrm{j}}\right)_{\mathrm{j}}^{\mathrm{n}-\mathrm{k}}, \quad \mathrm{k}=1,2, \ldots, \mathrm{n}_{\mathrm{j}} ; \mathrm{j}=1,2, \ldots, \mathrm{J}$,

where $\mathrm{k} !=1 * 2 * 3 * \ldots * \mathrm{k}$.

The total number of arrivals during $[\mathbf{a}, \mathbf{a}+15)$ is the sum of binomially distributed random variables, over the forecast arrival time buckets.

The calculation of the distribution of the sum of binomially distributed values can be simplified if the normal approximation of binomial distribution is used. A binomial distribution with parameters $n_{j}$ and $p_{j}$ can be approximated by a normal distribution ${ }^{11}$, with mean $n_{j} p_{j}$ and variance $n_{j} p_{j}\left(1-p_{j}\right)$

The expected total number of aircraft $\mathrm{E}(\mathbf{a})$ that would arrive at the $[\mathbf{a}, \mathbf{a}+15)$ interval (starting at $\mathbf{a}$ ) is equal to

$\mathrm{E}(\mathbf{a})=\sum_{j=1}^{J} n_{j} p_{j}$

Assuming independence of distributions of number of aircraft from each bucket that can arrive at the [a, a +15 ) interval, the variance $\sigma^{2}(\mathbf{a})$ of the number of aircraft predicted to arrive at $[\mathbf{a}, \mathbf{a}+15)$ is approximated by

$\sigma^{2}(\mathbf{a})=\sum_{j=1}^{J} n_{j} p_{j}\left(1-p_{j}\right)$

In these equations, again:

$\mathrm{n}_{\mathrm{j}}$ - number of flights with ETAs in the $\mathrm{j}^{\text {th }}$ bucket

$\mathrm{p}_{\mathrm{j}}$ - probability that a flight in the $\mathrm{j}^{\text {th }}$ bucket will arrive in $[\mathbf{a}, \mathbf{a}+15)$

Return to the above example on determining conditional probability for individual flight to arrive in [1200, $1215)$ interval if they are forecasted to arrive at four 15 -minute buckets from $[1130,1145)$ to $[1215,1230)$. The probability values are shown in Eqs. (3) - (6), above. Table 3 reproduces the probabilities from Eqs. (4) - (6) in case of three $(\mathrm{J}=3) 15$-minute intervals: the interval of interest $[1200,1215)$ and two adjacent buckets, $[1145,1200)$ and $[1215,1230)$.

Table 3. The Example of Considering Three Adjacent Buckets

\begin{tabular}{|c|c|c|}
\hline $\begin{array}{c}\text { n: Number of forecast } \\
\text { aircraft }\end{array}$ & Forecast arrival bucket & $\begin{array}{c}\mathbf{p}_{\mathbf{j}} \text { : Probability of arrival in } \\
\text { interval [1200, 1215) }\end{array}$ \\
\hline $\mathrm{D}(1145)$ & $1145-1200$ & 0.21 \\
\hline $\mathrm{D}(1200)$ & $1200-1215$ & 0.47 \\
\hline $\mathrm{D}(1215)$ & $1215-1230$ & 0.14 \\
\hline $\mathrm{D}(\mathrm{other})$ & Not in $1145-1230$ & Small \\
\hline
\end{tabular}

In the case of Table 3 and according to Eq. (9), the expected number of aircraft for the interval starting at 1200 , $\mathrm{E}(1200)$, is then given by

$\mathrm{E}(1200)=0.21 \mathrm{D}(1145)+0.47 \mathrm{D}(1200)+0.14 \mathrm{D}(1215)+\mathrm{pD}($ other $)$, where $\mathrm{pD}$ (other) is a to-be-determined adjustment, representing the last line in Table 3 with small probability $\mathrm{p}$. 
Equation (10) leads to the following formula for the variance $\sigma^{2}(1200)$ of the aircraft count for the 15 -minute interval starting at 1200 :

$$
\sigma^{2}(1200)=0.21(1-0.21) \mathrm{D}(1145)+0.47(1-0.47) \mathrm{D}(1200)+0.14(1-0.14) \mathrm{D}(1215)+\mathrm{p}(1-\mathrm{p}) \mathrm{D}(\text { other })
$$

Equation (12) can be simplified by noting that in the last term, $\mathrm{p}(1-\mathrm{p}) \mathrm{D}$ (other), $\mathrm{p}$ is assumed to be much smaller than 1 and , hence, $(1-\mathrm{p}) \approx 1$, so this term can be approximated by $\mathrm{pD}$ (other). As a result, Eq. (12) is transformed to

$$
\sigma^{2}(1200)=0.17 \mathrm{D}(1145)+0.25 \mathrm{D}(1200)+0.12 \mathrm{D}(1215)+\mathrm{pD}(\text { other })
$$

What is $\mathrm{pD}$ (other)? $\mathrm{D}$ (other) may represent a number of aircraft, each with a small probability $\mathrm{p}$ of arriving during the $[1200,1215)$ interval, and $\mathrm{pD}$ (other) can be interpreted as a residual error of the model. In Figure 4 (above), it includes the flights shown in Group 4.

There is a variety of possible ways of dealing with the residual error in the model. One approach is to use Eq. (11) and (13) with the shown coefficients and neglect the last term $\mathrm{pD}$ (other). This will create bias in the resulting model, since the $\mathrm{pD}$ (other) term is positive. A second approach is to use Eq. (11) and (13) without the last term $\mathrm{pD}$ (other) but adjust the coefficients to try to compensate for the error, using the following approach:

Since we have observed that the TFMS aggregate demand counts predictions are not significantly biased ${ }^{10}$, one might reasonably assume that the sum of the coefficients of the terms $\mathrm{D}(1145), \mathrm{D}(1200)$ and $\mathrm{D}(1215)$ in Eq. (11) should be close to 1 . The adjusting multiplier $\beta$ to those coefficients can be found from the following equation:

$$
\beta(0.21+0.47+0.14)=1 \text {, from which } \beta=1.22 .
$$

Equation (11) then becomes

$$
\mathrm{E}(1200)=1.22(0.21 \mathrm{D}(1145)+0.47 \mathrm{D}(1200)+0.14 \mathrm{D}(1215))=0.26 \mathrm{D}(1145)+0.57 \mathrm{D}(1200)+0.17 \mathrm{D}(1215)
$$

and the residual error $\mathrm{pD}$ (other) can be found from the following equation

$$
\mathrm{pD}(\text { other })=0.22(0.21 \mathrm{D}(1145)+0.47 \mathrm{D}(1200)+0.14 \mathrm{D}(1215))=0.05 \mathrm{D}(1145)+0.10 \mathrm{D}(1200)+0.03 \mathrm{D}(1215)
$$

Equation (13), when combined with Eq. (15), becomes

$$
\sigma^{2}(1200)=0.22 \mathrm{D}(1145)+0.35 \mathrm{D}(1200)+0.15 \mathrm{D}(1215)
$$

Note that both the expected demand counts and standard deviation of probabilistically predicted demand counts depend on deterministically predicted demand counts at all 15-minute intervals used in the probabilistic model.

What if one uses the forecast aircraft in the $[1200,1215)$ bucket only, as TFMS does? Then the expected number of flights predicted to arrive within $[1200,1215)$ interval is less than half of the deterministically predicted demand counts $\mathrm{D}(1200)$ :

$\mathrm{E}(1200)=0.47 \mathrm{D}(1200)$

The adjusting multiplier $\beta$ for this coefficient can be found from the following equation:

$$
0.47 \beta=1 \text {, }
$$

from which $\beta=2.13$, and

$\mathrm{pD}($ other $)=(\beta-1)(0.47 \mathrm{D}(1200))=0.53 \mathrm{D}(1200)$

The variance of predicted demand counts in this case, with $\mathrm{J}=1$, is equal to

$$
\sigma^{2}(1200)=(0.47(1-0.47)+0.53) \mathrm{D}(1200)=0.78 \mathrm{D}(1200),
$$


and the standard deviation is equal to

$\sigma(1200)=0.88 \sqrt{D(1200)}$

With the assumption that the probability distribution of demand counts is close to a normal distribution, the knowledge of an expected value and a variance of predicted demand counts make it possible to obtain a probabilistic prediction of the counts by using the table of percentiles for the normal distribution. If the expected value is equal to $\mathrm{E}$ and standard deviation is $\sigma$, then the probability that the predicted demand counts will be within the range of $(\mathrm{E} \pm \mathrm{m} \sigma$ ), where $\mathrm{m}$ determines the desired range in the numbers of standard deviations, can be found from the table for the normal distribution. For example, if $m=1$, then the probability is equal to 0.68 . If $m=2$, the probability is equal to 0.95 , i.e., with the probability of 0.95 , demand counts will be within the range from $(E-2 \sigma)$ to $(E+2 \sigma)$.

If one wants to know what is the threshold value for demand counts so that the predicted demand cannot exceed it with the certain probability, then the threshold value can be found from the table as a corresponding percentile. For example, the demand threshold that cannot be exceeded with the probability more than 0.25 is the 75 th percentile, and according to the table is equal to $(\mathrm{E}+0.68 \sigma)$. The threshold that determines the lower bound for demand counts to be below the threshold with 0.4 probability (not to be below this value with 0.6 probability) is the 40th percentile, which is equal to $(\mathrm{E}-0.26 \sigma)$. The expected value $\mathrm{E}$ itself represents the 50th percentile. It also worth noticing that, for symmetric, bell-shaped distributions, the expected value is the most likely value among other values of this distribution.

To illustrate how the expected value and the uncertainty range of probabilistic demand count predictions depend on the deterministic predictions, consider numerical examples with three cases of deterministic demand predictions for three consecutive 15-minute intervals (Table 4)

Table 4. Examples of Probabilistic Predictions

\begin{tabular}{|c|c|c|c|}
\hline & Case 1 & Case 2 & Case 3 \\
\hline $\mathrm{D}(1145)$ & 25 & 12 & 25 \\
\hline $\mathrm{D}(1200)$ & 20 & 20 & 20 \\
\hline $\mathrm{D}(1215)$ & 12 & 12 & 30 \\
\hline $\mathrm{E}(1200)$ from Eq. $(14)$ & 19.9 & 16.6 & 23.0 \\
\hline$\sigma^{2}(1200)$ from Eq. $(16)$ & 14.3 & 11.4 & 16.9 \\
\hline Standard Deviation $\sigma(1200)$ & 3.8 & 3.4 & 4.1 \\
\hline 2.3th percentile $(\mathrm{E}-2 \sigma)$ & 12.3 & 9.8 & 14.8 \\
\hline 25th percentile $(\mathrm{E}-0.68 \sigma)$ & 17.3 & 14.3 & 20.2 \\
\hline 75th percentile $(\mathrm{E}+0.68 \sigma)$ & 22.5 & 18.9 & 25.8 \\
\hline 97.7th percentile $(\mathrm{E}+2 \sigma)$ & 27.4 & 23.3 & 31.2 \\
\hline
\end{tabular}

In Case 1, $\mathrm{D}(1145)=25 ; \mathrm{D}(1200)=20 ; \mathrm{D}(1215)=12$.

According to Eqs. (14) and (16), the expected value and variance of probabilistically predicted demand counts for the 15-minute interval that starts at 1200 are:

$\mathrm{E}(1200)=0.26 * 25+0.57 * 20+0.17 * 12=6.5+11.4+2.0=19.9$

$\sigma^{2}(1200)=0.22 * 25+0.35 * 20+0.15 * 12=5.5+7.0+1.8=14.3$.

The standard deviation $\sigma(1200)$ is equal to 
$\sigma(1200)=\sqrt{14.3} \approx 3.8$

The 75th percentile of the predicted demand counts is equal to $\mathrm{E}(1200)+0.68 \sigma(1200)=19.9+2.6=22.5$. The 25 th percentile is equal to $\mathrm{E}(1200)-0.68 \sigma(1200)=19.9-2.6=17.3$. This means that with the probability 0.75 the demand counts will not exceed 22.5, and will not be smaller than 17.3. Moreover, with the 0.95 probability, the demand counts will be within the range of $\pm 2 \sigma$ around expected demand, i.e., within the range from 12.4 to 27.4 .

With this combination of demand counts at the three adjacent intervals, the expected value $\mathrm{E}(1200)=19.9$ appeared nearly equal to the deterministic prediction $\mathrm{D}(1200)=20$ for the 15 -minute interval. Figure 5 illustrates this case with the range of uncertainty in demand prediction between 25 th and 75 th percentiles. Both expected demand and deterministically predicted demand are close to and in the middle of the uncertainty range.

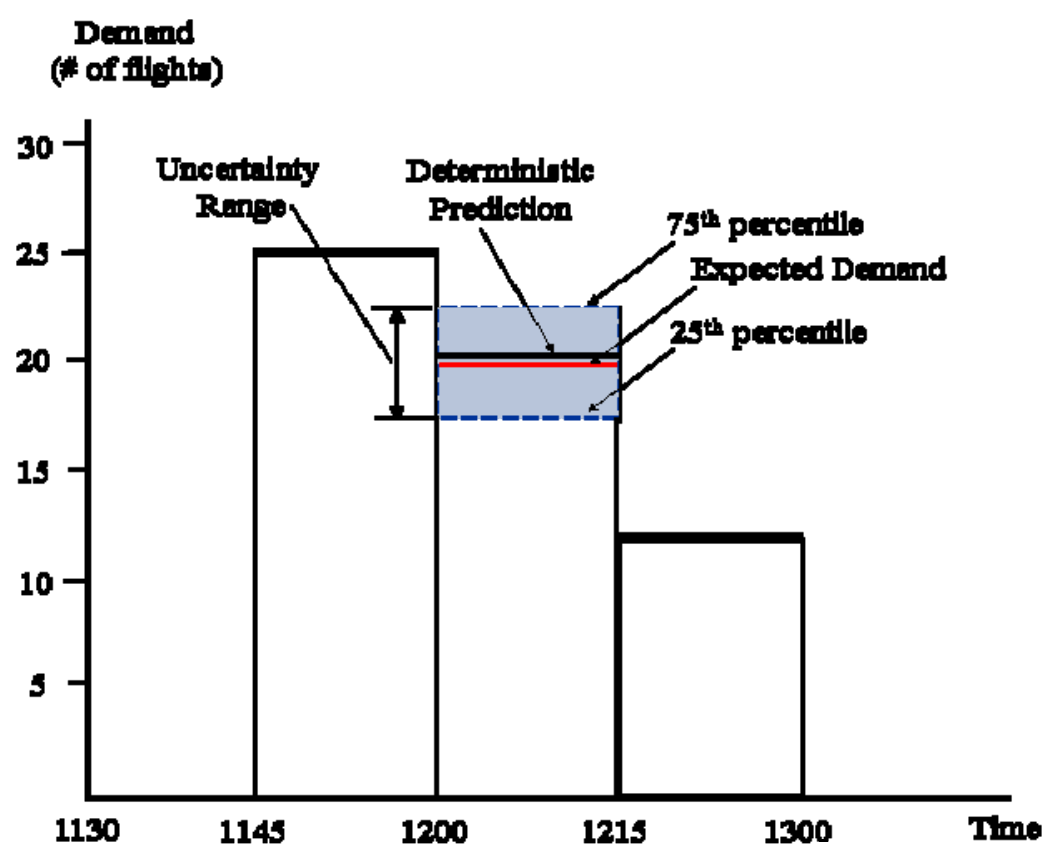

Figure 5. Case 1: Probabilistic vs. Deterministic Prediction

The calculations for Case 2 and Case 3 are similar to those for Case 1, and the results were presented in Table 4. They are shown graphically in Figures 6 and 7 . 

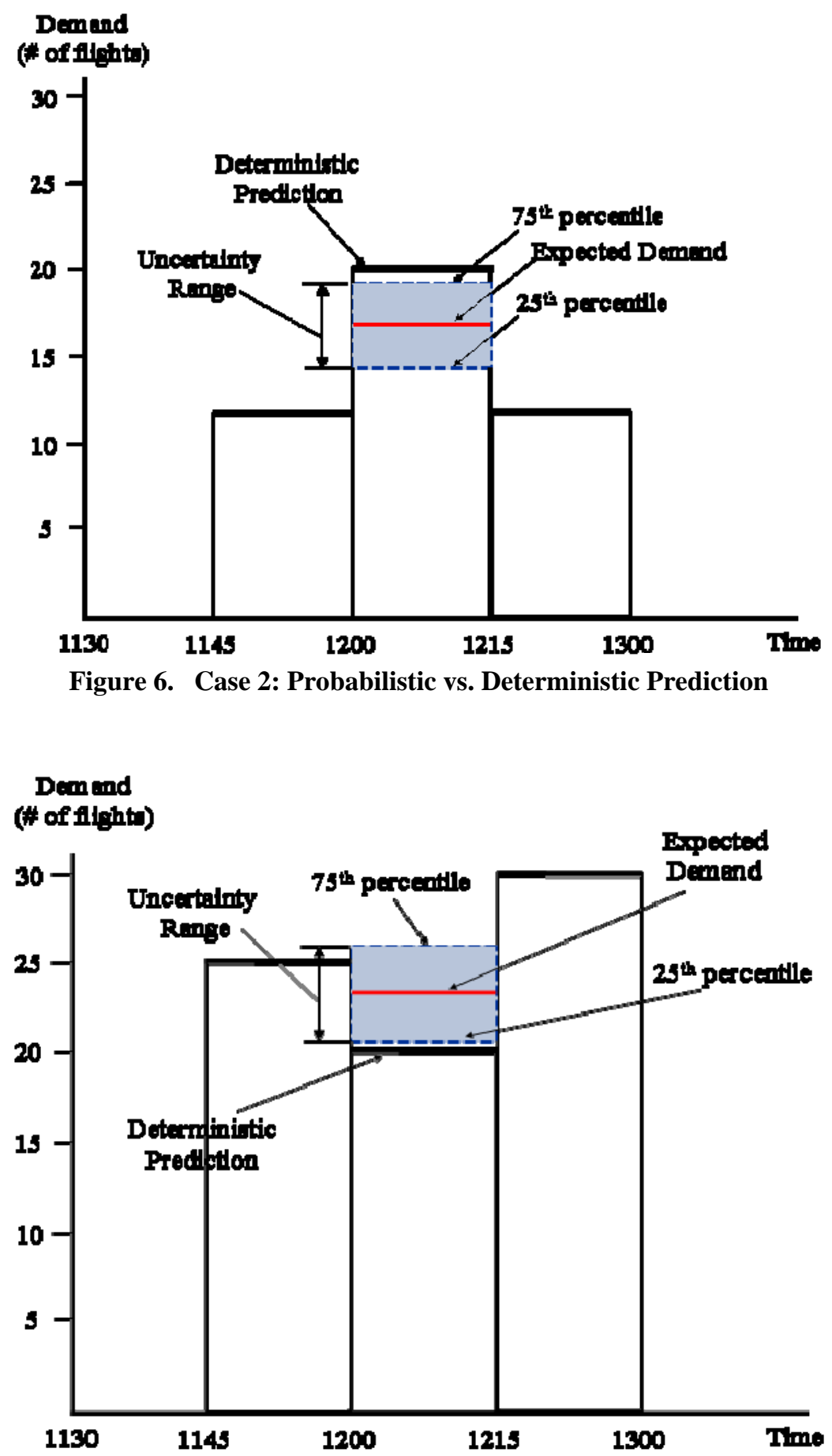

Figure 7. Case 3: Probabilistic vs. Deterministic Prediction

Note that, unlike Case 1, in both Case 2 and Case 3, the deterministic prediction of 20 flights is outside the uncertainty range between the 25th and 75th percentiles. In Case 2, the deterministic prediction is above the uncertainty range, but in Case 3 it is below (see Figures 6 and 7). It means that in both cases, the probability of traffic demand of 20 flights in the 1200 interval is smaller than 0.25 . 
These examples illustrate probabilistic demand prediction: it is measured by the expected value of demand counts and by the range of uncertainty around the expected value that covers the area within which predicted demand counts could have their values with a certain probability. The range is limited by the upper and lower bounds that correspond to probabilities for predicted demand to be higher and lower than a specified threshold. As for deterministic predictions, they make a significant contribution in calculating expected demand values and standard deviations that determine the level of predicted demand and parameters of prediction uncertainty (such as the range and probabilities), but the deterministic values themselves are not directly used as a probabilistic projection of demand. Instead, the expected demand counts, along with the uncertainty range covering the area around the expected demand with certain probability, determine the probabilistic demand predictions.

We can now give a general formulation of the algorithm for probabilistic demand predictions at 15-minute intervals based on characteristics of uncertainty in individual flights' ETA predictions and using deterministic demand count predictions at several consecutive 15-minute interval (for concreteness, we will consider three consecutive 15-minute intervals). The algorithm determines the probabilistic demand predictions at successive 15minute intervals by processing deterministic demand predictions within a sliding 45 -minute wide window comprising of three 15-minute intervals with the interval of interest in the middle of the window.

Consider a series of 15 -minute intervals $\Delta_{\mathrm{i}}$

$$
\Delta_{\mathrm{i}}=\left[\mathrm{t}_{0}+\mathrm{i}^{*} 15, \mathrm{t}_{0}+(\mathrm{i}+1)^{*} 15\right), \quad \mathrm{i}=1,2,3, \ldots
$$

where $t_{0}$ is a starting time.

Let $\mathrm{D}\left(\Delta_{\mathrm{i}}\right)$ be a deterministic prediction of demand counts for interval $\Delta_{\mathrm{i}}$.

Then, according to Eq. (14), the following formula determines the expected value $\mathrm{E}\left(\Delta_{\mathrm{i}}\right)$ of predicted demand counts for interval $\Delta_{\mathrm{i}}$ as a function of deterministic predictions for three consecutive intervals:

$\mathrm{E}\left(\Delta_{\mathrm{i}}\right)=0.26 \mathrm{D}\left(\Delta_{\mathrm{i}-1}\right)+0.57 \mathrm{D}\left(\Delta_{\mathrm{i}}\right)+0.17 \mathrm{D}\left(\Delta_{\mathrm{i}+1}\right), \mathrm{i}=2,3,4 \ldots$

According to Eq. (16), the variance $\sigma^{2}\left(\Delta_{\mathrm{i}}\right)$ of the predicted demand counts for interval $\Delta_{\mathrm{i}}$ is equal to

$\sigma^{2}\left(\Delta_{\mathrm{i}}\right)=0.22 \mathrm{D}\left(\Delta_{\mathrm{i}-1}\right)+0.35 \mathrm{D}\left(\Delta_{\mathrm{i}}\right)+0.15 \mathrm{D}\left(\Delta_{\mathrm{i}+1}\right), \mathrm{i}=2,3,4 \ldots$

Equations (20) and (21) sequentially determine the basic values for probabilistic demand predictions at each 15minute interval. In particular, knowledge of the standard deviations $\sigma\left(\Delta_{\mathrm{i}}\right)$ for each 15-minute interval makes it possible to determine desired percentiles to quantify the range of uncertainty around expected values $\mathrm{E}\left(\Delta_{\mathrm{i}}\right)$. For example, the $75^{\text {th }}$ percentile for interval $\Delta_{\mathrm{i}}$ is equal to $\mathrm{E}\left(\Delta_{\mathrm{i}}\right)+0.68 \sigma\left(\Delta_{\mathrm{i}}\right)$.

Consider a numerical example of deterministic 15-minute demand count predictions for 2.25 hours from 1200 to 1415. For this demand, expected values and variances were calculated by using Eq. (20) and (21).

Table 5 shows the calculation results along with deterministic predictions for each 15-minute interval.

Table 5. Example: Probabilistic vs. Deterministic Predictions

\begin{tabular}{|c|c|c|c|c|c|}
\hline Time Interval & $\begin{array}{c}\text { Deterministic } \\
\text { Demand }\end{array}$ & $\begin{array}{c}\text { Expected } \\
\text { Demand }\end{array}$ & $\begin{array}{c}\text { Expected Minus } \\
\text { Deterministic } \\
\text { Demand }\end{array}$ & Variance $\sigma^{2}$ & $\begin{array}{c}\text { Standard } \\
\text { Deviation } \sigma\end{array}$ \\
\hline $1200-1215$ & 20 & & & & \\
\hline $1215-1230$ & 12 & 14.48 & 2.48 & 11.0 & 3.32 \\
\hline $1230-1245$ & 16 & 16.49 & 0.49 & 11.99 & 3.46 \\
\hline $1245-1300$ & 25 & 22.15 & -2.85 & 15.57 & 3.95 \\
\hline $1300-1315$ & 22 & 21.25 & -0.75 & 15.15 & 3.89 \\
\hline $1315-1330$ & 13 & 16.19 & 3.19 & 12.09 & 3.48 \\
\hline $1330-1345$ & 18 & 15.34 & -2.66 & 10.66 & 3.26 \\
\hline $1345-1400$ & 10 & 14.63 & 4.63 & 11.21 & 3.35 \\
\hline $1400-1415$ & 25 & & & & \\
\hline
\end{tabular}


The table shows that the difference between deterministic and expected demand counts can be significant. For example, at [1345 - 1400) interval, the expected demand is more than $46 \%$ higher than the deterministic prediction. However, the standard deviations of probabilistic predictions do not vary much at different 15 -minute intervals.

Figure 8 illustrates the probabilistic representation of traffic demand count predictions in the form of bar charts with the range of uncertainty at each interval restricted by $25^{\text {th }}$ and $75^{\text {th }}$ percentiles using numerical results from Table 5. At each bar, the red lines and the thick black horizontal lines show the predicted expected and deterministic demand values, respectively. At some 15-minute intervals, the expected values are close to deterministic ones (e.g., intervals starting at 1200,1230 and 1300); at some intervals the deterministic predictions are much higher than expected demands and are outside the shown uncertainty ranges, which indicated a low probability for deterministic predictions (e.g., intervals starting at 1245, 1330 and 1400), and at some intervals the deterministic predictions are much lower than the expected values and also are outside the shown uncertainty range (see intervals starting at 1215, 1315 and 1345).

Figure 8 illustrates another important property of probabilistic demand prediction: the expected demands are smoothing the deterministic demand profile and are reducing fluctuations of predicted 15-minute demands along the time period that make it more stable.

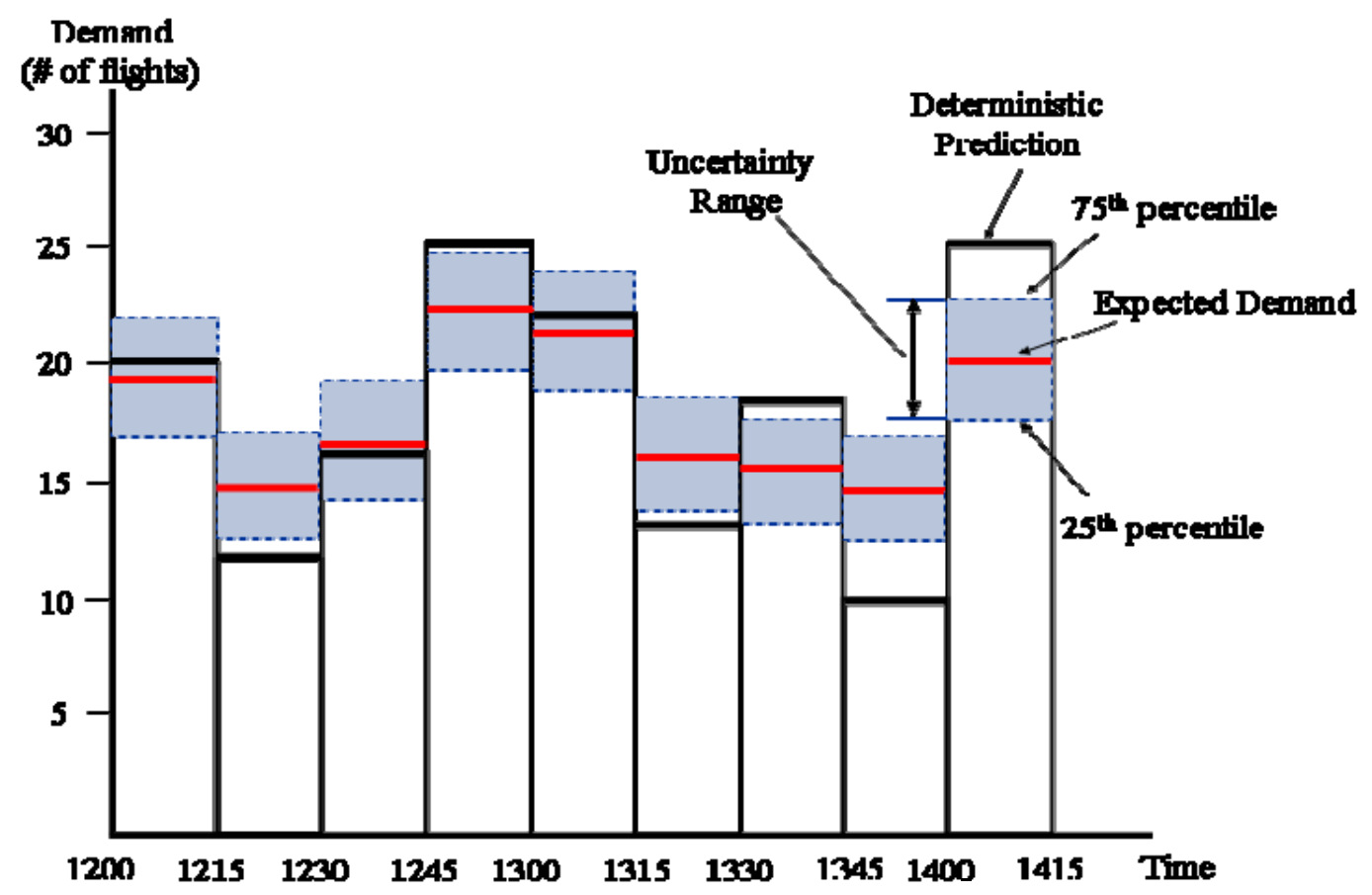

Figure 8. Probabilistic Predictions of Traffic Demand Counts

Another measure of interest is hourly demand, as TFM specialists might consider predictions for hourly demands during a several-hour period when making decisions on TMIs.

The example in Table 5 shows that, although there might be significant differences between expected and deterministic predictions at 15 -minute intervals, there is not much difference in the hourly counts. As Table 5 covers only two and a quarter-hour period, we will illustrate it on the hourly counts within a sliding one-hour window that moves consecutively by 15 minutes. The results of the comparison are presented in Table 6 . 
Table 6. Hourly Demand Predictions: Expected vs. Deterministic Counts

\begin{tabular}{|c|c|c|c|}
\hline $\begin{array}{c}\text { One-hour } \\
\text { Period }\end{array}$ & $\begin{array}{c}\text { Deterministic } \\
\text { Demand }\end{array}$ & $\begin{array}{c}\text { Expected } \\
\text { Demand }\end{array}$ & $\begin{array}{c}\text { Expected Minus } \\
\text { Deterministic } \\
\text { Demand }\end{array}$ \\
\hline $1215-1315$ & 74 & 75 & 1 \\
\hline $1230-1330$ & 76 & 75 & -1 \\
\hline $1245-1345$ & 78 & 74 & -4 \\
\hline $1300-1400$ & 63 & 66 & 3 \\
\hline
\end{tabular}

Table 6 illustrates that the hourly demand counts might not differ much. Further analysis will be needed to more thoroughly explore the differences between the hourly demand counts.

The above results on probabilistic prediction of traffic demand counts were obtained while using the following simplifying assumptions:

- Aircraft arrivals are statistically independent

- Binomial probability distribution for predicted demand counts is approximated by the normal distribution

- The probabilistic demand forecast provides an unbiased estimation of demand counts.

\section{E. Comparison with Previous Work}

In our 2007 paper and report ${ }^{9}, 10$, we analyzed the accuracy of TFMS predictions of aggregate traffic demand counts and explored ways to improve prediction accuracy. The analysis was entirely based on 15-minute counts without usage of individual flight data. Although both this paper and the 2007 paper used TFMS data as the basis for analysis, the 2007 paper used an earlier data set.

The 15-minute arrival counts were examined for the same 9 airports as in this paper for look-ahead times ranging from 0.5 to 6 hours. For those look-ahead times in the $1.25-2$ hour range, the standard deviations ranged between 2.4 and 3.1 for those moderately busy airports with between 6 to 13 arrivals in 15 minutes ${ }^{10}$.

Analytical results were obtained in this study for estimating the accuracy of demand count predictions. In particular, Eq. (19) in Section IV.D presents a closed form approximation for the standard deviation of demand counts, based on the number of flights deterministically forecast in a single 15-minute interval. If 9 flights are forecast in 15 minutes, Eq. (19) yields a standard deviation of 2.6, consistent with what was observed in the TFMS data.

In our previous study, we proposed a linear regression model for 15 -minute count predictions that made use of the count predictions in adjacent intervals ${ }^{9,10}$. Linear regressions were performed on actual count data to determine weight coefficients $\mathrm{a}, \mathrm{b}$, and c for deterministic demand predictions at three consecutive intervals, as well as a constant term $\mathrm{k}$. Using the notation from the previous section, the regression model looks like

$\mathrm{E}(1200)=\mathrm{a} \mathrm{D}(1145)+\mathrm{b} \mathrm{D}(1200)+\mathrm{c} \mathrm{D}(1215)+\mathrm{k}$

In this earlier work, examination of the regression results revealed that reasonable values of the coefficients were

$\mathrm{a}=0.25, \mathrm{~b}=0.55, \mathrm{c}=0.2$ and $\mathrm{k}=0$, so that

$\mathrm{E}(1200)=0.25 \mathrm{D}(1145)+0.55 \mathrm{D}(1200)+0.2 \mathrm{D}(1215)$

Table 7 illustrates the similarity between these predictions and predictions just derived. 
Table 7. Coefficients in Airport Arrival Demand Models

\begin{tabular}{|c|c|c|}
\hline & $\begin{array}{c}\text { Equation 20 } \\
\text { (this paper) }\end{array}$ & $\begin{array}{c}\text { Equation 23 } \\
\text { (from previous paper }{ }^{9} \text { ) }\end{array}$ \\
\hline $\mathrm{D}(1145)$ & 0.26 & 0.25 \\
\hline $\mathrm{D}(1200)$ & 0.57 & 0.55 \\
\hline $\mathrm{D}(1215)$ & 0.17 & 0.20 \\
\hline
\end{tabular}

The similarity of these linear prediction functions, obtained via different methodologies and data sets, demonstrates the viability of proposed approach to probabilistic prediction of traffic demand.

Unlike the previous work that was limited by constructing the regression model for demand counts, this work developed a methodology that, in addition to regression model, provided the constructive way for quantifying the prediction uncertainty and its probabilistic properties.

\section{Conclusion}

TFMS currently makes its aggregate traffic demand predictions based on deterministic projections of traffic and neglects random errors in predictions. The purpose of this study was to

- Analyze the errors in time predictions for individual flights and characterize the accuracy of TFMS flightby-flight prediction data

- Use these characteristics of uncertainty to determine the probability for an aircraft to arrive at an airport at any given time

- Relate the uncertainty in predictions for individual flights to uncertainty in predictions for 15-minute aggregate demand counts.

Analysis of accuracy of predictions for individual flights was conducted for flights' airport arrival times. Comparative analyses of prediction errors were performed for different flights' status (active and proposed) as well as for different look-ahead times (from one to two hours and from two to three hours). As a result of analysis of TFMS historical data, the characteristics of prediction errors were estimated to characterize uncertainty in flight arrival time predictions.

For flights' airport arrival times, the results were as follows:

- Predictions for active flights are significantly more accurate than for proposed flights, with a much narrower range of uncertainty for the active flights. For active flights the prediction errors are within \pm 15 minute range, whereas for the proposed flights the errors range from -45 to +25 minutes.

- There is little difference in accuracy with shorter (1 to 2 hour) or longer (2 to 3 hour) LAT.

- For active flights, the probability distributions of prediction errors are nearly symmetric with zero average error.

- For proposed flights, the prediction errors are biased with median error of approximately -7 minutes that correspond to late arrivals. The probability distributions of prediction errors are asymmetric with heavier left-hand tails that reflect the tendency for proposed flights to arrive, on average, later than predicted.

The results of analysis of uncertainty in individual flights predictions were used to develop probabilistic predictions of aggregate traffic demand counts. A methodology was developed for determining characteristics of uncertainty in predictions of airport aggregate arrival demand counts based on characteristics of uncertainty in predictions of individual flights' arrival time at an airport.

Analytical methods were used to obtain the probability distributions for traffic demand count predictions. The probabilistic characteristics of traffic demand counts for a specific time interval were determined from the set of flights that included not only the flights with ETAs within the time interval of interest but also the flights with ETAs in the immediate preceding and following adjacent intervals. The probabilistic representation of aggregate traffic demand counts includes the expected value along with the range of uncertainty around the expected value restricted by specific percentiles (e.g., 25 and 75 percentiles). Numerical examples illustrate the advantages of probabilistic demand predictions over deterministic ones. The probabilistic demand predictions along with predicted capacities then can be used together in probabilistic TFM to help determine the likelihood of congestion at airports. 


\section{References}

${ }^{1}$ Meyn, Larry A., "Probabilistic Methods for Air Traffic Demand Forecasting," Paper number 2002-4276, AIAA Guidance, Navigation, and Control Conference and Exhibit, Monterey, CA, 2002.

${ }^{2}$ Wanke, C., Mulgund, S., Greenbaum, D., and Song, L., "Modeling Traffic Prediction Uncertainty for Traffic Flow Management Decision Support," AIAA Guidance, Navigation, and Control Conference and Exhibit, Providence, RI, August, 2004.

${ }^{3}$ Zobell, Stephen, Craig Wanke, and Lixia Song, "Probabilistic Airspace Congestion Management," Paper number 20057433, AIAA 5th Aviation, Technology, Integration, and Operations Conference (ATIO), Arlington, VA, 2005.

${ }^{4}$ Wanke, Craig, Lixia Song, Stephen Zobell, Daniel Greenbaum, and Sandeep Mulgund, "Probabilistic Congestion Management," $6^{\text {th }}$ USA/Europe ATM R\&D Seminar, Baltimore, MD, 2005.

${ }^{5}$ Hunter, George, and Kris Ramamoorthy, "A Trajectory-Based Probabilistic TFM Evaluation Tool and Experiment", ICNS Conference, Baltimore, MD, May 2006

${ }^{6}$ Ramamoorthy, K.; Boisvert, B.; Hunter, G., "A Real-Time Probabilistic Traffic Flow Management Evaluation Tool”, $25^{\text {th }}$ Digital Avionics Systems Conference, 2006 IEEE/AIAA, pp. 1 - 13, Portland, OR, 15-19 Oct. 2006.

${ }^{7}$ Wanke, C., and Greenbaum, D., "Incremental, Probabilistic Decision-Making for En Route Traffic Management", $7^{\text {th }}$ USA/Europe ATM R\&D Seminar, Barcelona, Spain, July 2007

${ }^{8}$ J. DeArmon, C. Wanke, D. Greenbaum, "Probabilistic TFM: Preliminary Benefits Analysis of an Incremental Solution Approach", MITRE, 2007.

${ }^{9}$ Gilbo, Eugene and Scott Smith, "A New Model to Improve Aggregate Air Traffic Demand Predictions," Paper number 2007-6450, AIAA Guidance, Navigation, and Control Conference and Exhibit, Hilton Head, SC, 2007.

${ }^{10}$ Gilbo, Eugene and Scott Smith, "Reducing Uncertainty in ETMS Aggregate Traffic Demand Predictions," Volpe National Transportation Systems Center, Report no. VNTSC-CE-07-01, March 2007.

${ }^{11}$ NIST/SEMATECH e-Handbook of Statistical Methods, http://www.itl.nist.gov/div898/handbook/, accessed in January 2008. 